\section{Biometry of the silicone oil-filled eye}

\author{
Abstract \\ Purpose The advent of silicone oil tamponade \\ has resulted in improved success rates in \\ complicated retinal detachment surgery. Its \\ use, however, can induce cataract formation in \\ phakic eyes. In selected patients, removal of \\ silicone oil can be combined with \\ phacoemulsification of the cataract and \\ intraocular lens (IOL) implantation, thus \\ avoiding a further operation. This, however, \\ poses a problem when trying to decide the \\ power of IOL to be used, since the \\ echographically measured axial length $(A L)$ of \\ an eye is greater in the presence of silicone oil. \\ We performed ultrasound examination in the \\ presence of silicone oil of viscosity $\mathbf{1 3 0 0}$ \\ centistokes, in order to determine whether the \\ measured AL varied from the true AL by a \\ constant factor.
}

Methods The ALs of 7 phakic eyes were measured by A-mode echography, with and without silicone oil of viscosity 1300 centistokes in the posterior segment. The retina was attached in all cases. The control group consisted of 6 phakic eyes with attached retinae undergoing vitrectomy without the use of silicone oil. The ALs in the control group were measured before and after vitrectomy.

Results The mean ratio of true AL to measured AL in the presence of silicone oil was 0.71 (standard deviation 0.01 ; range 0.70-0.73; median 0.71) in the 7 eyes in this study. In the control group, vitrectomy appeared to have no significant effect on AL. Conclusions We have established a constant which corrects for the apparent increase in $\mathrm{AL}$ induced by silicone oil of viscosity 1300 centistokes. This conversion factor, when used in existing biometry formulae (SRK/T), allows estimation of the power of IOL required in eyes undergoing combined cataract extraction, removal of silicone oil and lens implantation.

Key words Axial length, Biometry, Echography, Intraocular lens, Silicone oil

Silicone oil plays an increasingly important role as a replacement material for the vitreous in complex retinal detachments. Its use as a tamponade allows successful retinal reattachment in some cases of otherwise
D.C. MURRAY, T. POTAMITIS, P. GOOD, G.R. KIRKBY, M.T. BENSON intractable retinal detachment. ${ }^{1-5}$ If left in, there is a high incidence of complications including band and/or vascularised keratopathy, late corneal decompensation, glaucoma, hypotony and cataract. ${ }^{1-7}$ In 1985, Gonvers ${ }^{2}$ described a technique in which silicone oil was used as a temporary tamponade for 4-6 weeks. This resulted in reduction of the long-term complications. At present, the most common complication in phakic eyes after the temporary use of silicone oil to treat complicated retinal detachments is cataract formation. ${ }^{2,4,5}$ In selected patients, removal of silicone oil can be combined with phacoemulsification of the cataract and intraocular lens (IOL) implantation, ${ }^{6}$ thus avoiding a further operation. Significant post-operative refractive errors may result because the echographically measured AL in eyes containing silicone oil is greater than the true AL (Fig. 1). This is because the speed of sound in silicone oil $(987 \mathrm{~m} / \mathrm{s}$ in silicone oil of viscosity 1000 centistokes $^{8}$ ) is slower than in vitreous humour $\left(1532 \mathrm{~m} / \mathrm{s}^{8,9}\right)$ (Table 1). The echographically measured vitreous cavity depth, and therefore the $\mathrm{AL}$, are overestimated. The true AL may be calculated by determining the length of the anterior chamber, lens and vitreous cavity separately and adding these values together. ${ }^{7} \mathrm{AL}=\mathrm{ACD}+$ $\mathrm{LT}+\mathrm{VCD}(\mathrm{AL}=$ axial length; $\mathrm{ACD}=$ anterior chamber depth; LT = lens thickness; $\mathrm{VCD}=$ vitreous cavity depth). In practice this is not easily done since most commercially available echography machines have the speed of sound through the vitreous cavity preset at $1532 \mathrm{~m} / \mathrm{s}$.

Theoretically, the speed of sound in silicone oil of viscosity 1000 centistokes compared with the speed of sound in vitreous humour decreases by a factor of $0.64(987 \mathrm{~m} / \mathrm{s} \div 1532$ $\mathrm{m} / \mathrm{s}$ ). It is therefore possible to calculate the true depth of the vitreous cavity $\left(\mathrm{VCD}_{\text {oil }} \times 0.64\right)$ and hence the true AL. In fact, one study has documented a $50 \%$ echographic prolongation of the length of the vitreous cavity because of the delayed velocity of sound in silicone oil. ${ }^{10} \mathrm{~A}$ later study confirmed that it takes approximately 1.5 times as long for an ultrasound pulse to traverse a vitreous cavity filled with silicone oil as it does to travel the same distance through normal vitreous. ${ }^{11}$

\footnotetext{
D.C. Murray

T. Potamitis

P. Good

G.R. Kirkby

M.T. Benson

Birmingham and Midland

Eye Centre

Birmingham, UK

D.C. Murray

Birmingham and Midland Eye Centre

City Hospital NHS Trust

Dudley Road

Birmingham B18 7QU, UK

Tel: $+44(0) 1215076807$

Fax: +44 (0)121 5076853

e-mail: desiree@mcmail.com

Presented in part at the British and Eire Association of Vitreoretinal Surgeons, Birmingham, October 1997

Received: 10 September 1998

Accepted in revised form: 15 March 1999
} 
A

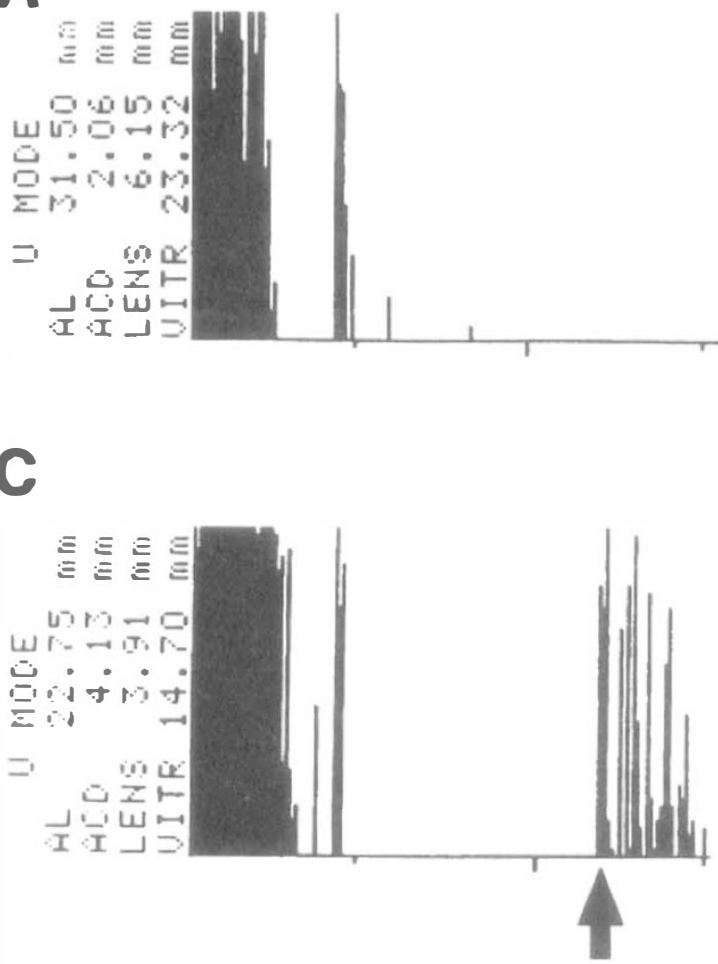

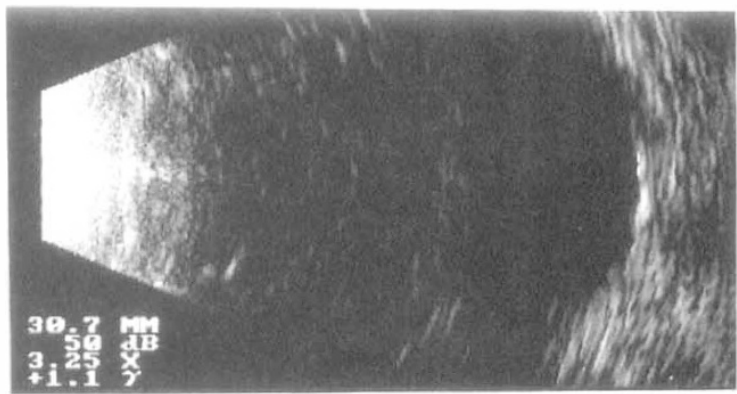

D

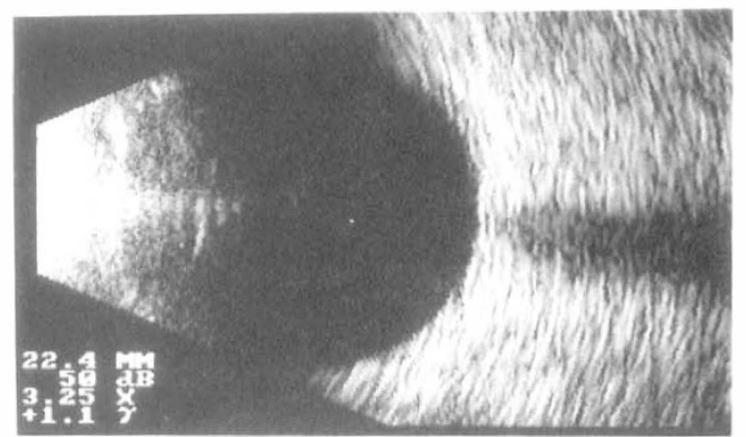

Fig. 1. (A) A-scan echography of a phakic eye with the vitreous cavity filled with silicone oil ${ }^{\mathrm{a}}$. The retinal echo is easily discernible: arrow. (B) $B$-scan echography (using 50 decibel sound intensity) of same phakic eye with the vitreous cavity filled with silicone oil ${ }^{a}$. (The axial length measures less with the B-scan than with the A-scan.) (C) A-scan echography of same phakic eye following removal of silicone oil ${ }^{\text {a }}$. The retinal echo is demonstrated: arrow (D) B-scan echography of same phakic eye following removal of silicone oil. (Note the apparent difference in axial length between the silicone-oil-filled $d^{\mathrm{a}}$ eye and vitrectomised eye. ${ }^{\mathrm{a}}$ Viscosity 1300 centistokes. AL, axial length; $A C D$, anterior chamber depth; LENS, lens thickness; VITR, vitreous cavity depth.

ACD, LT and VCD are not, however, always known because not all biometry machines record these variables. We performed echographic examination with and without silicone oil in the posterior segment, in 7 phakic eyes, to determine whether the measured length of the vitreous cavity and the measured axial length ( $\mathrm{AL})$ varied from the true lengths by a constant factor(s).

\section{Materials and methods}

ALs were measured in 7 phakic eyes with silicone oil in the posterior segment. Successful retinal reattachment with the aid of silicone oil (Oxane, Chauvin; viscosity 1300 centistokes) as tamponade had been achieved in all cases. Oil-fill was always as complete as possible. The AL measurements were repeated following removal of silicone oil from the posterior segment. The control

Table 1. Velocity of ultrasound in various media ${ }^{7-9}$

\begin{tabular}{lc}
\hline Medium & Propagation velocity $(\mathrm{m} / \mathrm{s})$ \\
\hline Air & 330 \\
Water & 1480 \\
Cornea/lens & 1641 \\
Aqueous/vitreous $^{-}$ & 1532 \\
Silicone oil $^{a}$ & 987 \\
\hline
\end{tabular}

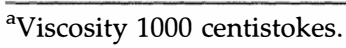

group consisted of 6 phakic eyes with attached retinae undergoing vitrectomy without the use of silicone oil. ALs were measured, using A-mode echography, prior to and following vitrectomy.

A-mode echography (10 $\mathrm{MHz}$ central frequency, Canon KVI biometry apparatus) was used to measure the AL of the silicone oil-filled eye. Measurements were recorded with the patient sitting upright and the transducer held so that the ultrasound beam was perpendicular to the globe. In all eyes, B-scans (using 50 decibel sound intensity) were also performed in order to ensure that the values of $A L$, as measured by $A$ - and $B$-scanning, were similar. This ensured that the retinal echo on A-scan was not an artefact, since it corresponded to the macular echo on the B-scan (Fig. 1). A-scanning was then used to measure the AL after the silicone oil had been removed from the posterior segment of the eye. The ratio between the AL in the vitrectomised eye and the $\mathrm{AL}$ in the silicone oil-filled eye was calculated for all 7 eyes. The mean ratio was taken as the conversion factor required to estimate the true $\mathrm{AL}$ of the silicone oil-filled eye. The power of IOL required for emmetropia was determined using the SRK/T biometry formula. ${ }^{12}$ In the 7 eyes the power of IOL estimated by applying the conversion factor was compared with the power of IOL determined after removal of silicone oil. 
Table 2. Ratio of axial length without silicone oil to axial length in the presence of posterior segment silicone oil in 7 phakic eyes

\begin{tabular}{lccc}
\hline Patient no. & $\begin{array}{c}\mathrm{AL} \text { with oil } \\
(\mathrm{mm})\end{array}$ & $\begin{array}{c}\mathrm{AL} \text { without oil } \\
(\mathrm{mm})\end{array}$ & $\begin{array}{c}\text { Ratio } \mathrm{AL}_{\text {without }} \\
\text { oil } / \mathrm{AL}_{\text {with oil }}\end{array}$ \\
\hline 1 & 34.22 & 24.43 & 0.71 \\
2 & 32.48 & 22.67 & 0.70 \\
3 & 31.80 & 22.84 & 0.72 \\
4 & 31.65 & 23.08 & 0.73 \\
5 & 31.50 & 22.75 & 0.72 \\
6 & 31.14 & 22.12 & 0.71 \\
7 & 30.09 & 21.46 & 0.71 \\
Mean & 31.84 & 22.76 & 0.71 \\
SD & 1.28 & 0.91 & 0.01 \\
\hline
\end{tabular}

$\mathrm{AL}$, axial length.

\section{Results}

For the 7 silicone oil-filled eyes, ALs ranged from $30.09 \mathrm{~mm}$ to $34.22 \mathrm{~mm}$ (median $31.65 \mathrm{~mm}$; mean $31.84 \mathrm{~mm}$; standard deviation $1.28 \mathrm{~mm}$ ). After removal of silicone oil, the ALs ranged from $21.46 \mathrm{~mm}$ to $24.43 \mathrm{~mm}$ (median $23.08 \mathrm{~mm}$; mean $22.76 \mathrm{~mm}$; standard deviation $0.91 \mathrm{~mm})$.

The ratio of $\mathrm{AL}$ in the vitrectomised eye to $\mathrm{AL}$ in the silicone oil-filled eye ranged from 0.70 to 0.73 ; median 0.71 (Table 2 ). The mean ratio was 0.71 ; standard deviation 0.01 .

In the control group the ratio of the $\mathrm{AL}$ values before and after vitrectomy was effectively unity (mean \pm standard deviation, $0.98 \pm 0.02$; Table 3 ). Vitrectomy alone did not seem to have a significant effect on AL.

Four of the 7 eyes in the study group had ACD, LT and VCD measured on A-scan echography before and after removal of silicone oil (Table 4). In three eyes the ACD, LT and VCD were not recorded by the A-scan echographic machine because on the high gain required for dense lens opacities these parameters are not always recordable.

In all 7 eyes in the study group, the true AL was compared with the calculated AL using the conversion factor determined in this study, i.e. $\mathrm{AL}_{\text {without oil }}=\mathrm{AL}_{\text {oil }} \times$ 0.71 (Table 5). In the 4 eyes with ACD, LT and VCD measurements available, the ALs were also calculated as follows (Table 5):

$\mathrm{AL}_{\text {without oil }}=\mathrm{ACD}_{\text {oil }}+\mathrm{LT}_{\text {oil }}+\left[\mathrm{VCD}_{\text {oil }} \times(\right.$ Sound velocity $_{\text {oil }} \div$ Sound $_{\text {velocity }}$ vitreous $\left.)\right]$

Table 3. Ratio of axial length in vitrectomised eye to axial length before vitrectomy in 6 phakic patients

\begin{tabular}{lccc}
\hline $\begin{array}{l}\text { Patient } \\
\text { no. }\end{array}$ & $\begin{array}{c}\text { AL before } \\
\text { vitrectomy }(\mathrm{mm})\end{array}$ & $\begin{array}{c}\text { AL after } \\
\text { vitrectomy }(\mathrm{mm})\end{array}$ & $\begin{array}{c}\text { Ratio } \mathrm{AL}_{\text {after }} / \\
\mathrm{AL}_{\text {before }}\end{array}$ \\
\hline 1 & 27.45 & 26.50 & 0.96 \\
2 & 24.61 & 24.04 & 0.98 \\
3 & 24.16 & 24.18 & 1.00 \\
4 & 24.09 & 23.63 & 0.98 \\
5 & 22.58 & 22.54 & 1.00 \\
6 & 21.78 & 21.58 & 0.99 \\
Mean & 24.11 & 23.74 & 0.98 \\
SD & 1.96 & 1.67 & 0.02 \\
\hline
\end{tabular}

$\mathrm{AL}$, axial length.
Table 4. Axial length, anterior chamber depth, lens thickness and vitreous cavity depth with and without posterior segment silicone oil (viscosity 1300 centistokes) in 4 phakic eyes

\begin{tabular}{|c|c|c|c|c|}
\hline & \multicolumn{4}{|c|}{ Patient no. } \\
\hline & 1 & 4 & 5 & 7 \\
\hline \multicolumn{5}{|l|}{ Axial length (mm) } \\
\hline With oil & 34.22 & 31.65 & 31.50 & 30.09 \\
\hline Without oil & 24.43 & 23.08 & 22.75 & 21.46 \\
\hline \multicolumn{5}{|l|}{ Anterior chamber depth (mm) } \\
\hline With oil & 2.77 & 2.05 & 2.06 & 2.45 \\
\hline Without oil & 3.46 & 2.85 & 4.13 & 2.11 \\
\hline \multicolumn{5}{|l|}{ Lens thickness (mm) } \\
\hline With oil & 4.10 & 3.32 & 6.15 & 3.74 \\
\hline Without oil & 4.21 & 5.17 & 3.91 & 4.21 \\
\hline \multicolumn{5}{|l|}{ Vitreous cavity depth (mm) } \\
\hline With oil & 27.22 & 26.12 & 23.52 & 23.80 \\
\hline Without oil & 16.76 & 15.14 & 14.70 & 15.16 \\
\hline Ratio $^{a}:$ & & & & \\
\hline $\begin{array}{l}\text { Vitreous cavity depth } \text { without oil } \\
\text { Vitreous cavity depth with oil }\end{array}$ & 0.62 & 0.58 & 0.62 & 0.64 \\
\hline
\end{tabular}

$\mathrm{AL}_{\text {without oil }}=\mathrm{AL}$ of vitrectomised eye (true $\mathrm{AL}$ )

$\mathrm{AL}_{\text {oil }}=$ measured $\mathrm{AL}$ in the presence of silicone oil ${ }^{*}$ $\mathrm{ACD}_{\mathrm{oil}}=$ anterior chamber depth in the presence of silicone oil*

$\mathrm{LT}_{\text {oil }}=$ lens thickness in the presence of silicone oil ${ }^{*}$ $\mathrm{VCD}_{\text {oil }}=$ measured vitreous cavity depth in the presence of silicone oil*

Sound velocity $_{\mathrm{oil}}=$ velocity of sound in silicone oil $^{* *}=$ $987 \mathrm{~m} / \mathrm{s}$

Sound velocity vitreous $=$ velocity of sound in vitreous $=$ $1532 \mathrm{~m} / \mathrm{s}$

*Viscosity 1300 centistokes

**Viscosity 1000 centistokes

The mean AL of the 7 eyes following removal of silicone oil was $22.76 \mathrm{~mm}$ (standard deviation 0.91). Mean AL of the 7 eyes using a conversion factor of 0.71 was $22.63 \mathrm{~mm}$ (standard deviation 0.91). The mean percentage error was $-0.57 \%$ (Table 5 ). For the 4 eyes with data available, mean AL using a correction factor of 0.64 for the $\mathrm{VCD}_{\text {oil }}$ was $22.76 \mathrm{~mm}$ (standard deviation 1.27). The mean AL of these 4 eyes after removal of silicone oil was $22.93 \mathrm{~mm}$ (standard deviation 1.22). The mean percentage error was $-0.74 \%$ (Table 5 ).

The SRK/T formula was used to compare the measured power of IOL and the estimated power of IOL (using the conversion factor of 0.64 to determine $\mathrm{VCD}_{\text {without oil }}$ and/or the conversion factor of 0.71 to determine true $\mathrm{AL}$ ) required for emmetropia in 7 eyes (Table 6). The difference between the estimated and the measured power of IOL ranged from +0.03 to +2.07 dioptres (median 0.93 dioptres; mean 0.88 dioptres; standard deviation 0.68$)$, but $6(86 \%)$ of the 7 eyes had a difference of $\leqslant 1.00$ dioptre (to the nearest 0.50 dioptre). 


\begin{tabular}{|c|c|c|c|}
\hline Patient no. & True AL (mm) & $\mathrm{AL}_{\text {oil }} \times 0.71(\mathrm{~mm})$ & $\begin{array}{c}\left.\mathrm{ACD}_{\text {oil }}+\mathrm{LT}_{\text {oil }}+(\mathrm{VCD})_{\text {oil }} \times 0.64\right)^{a, d} \\
\mathrm{ACD}_{\text {oil }}+\mathrm{LT}_{\text {oil }}+\left(\mathrm{VCD} \mathrm{Dil}_{\text {oil }} \times 0.62\right)^{a_{e}}(\mathrm{~mm})\end{array}$ \\
\hline \multirow[t]{2}{*}{1} & $24.43^{c}$ & 24.30 & $24.29^{a, d}$ \\
\hline & & & $23.75^{a, e}$ \\
\hline 2 & 22.67 & 23.06 & $-^{b}$ \\
\hline 3 & 22.84 & 22.72 & $-^{b}$ \\
\hline \multirow[t]{2}{*}{4} & $23.08^{c}$ & 22.47 & $22.09^{a, d}$ \\
\hline & & & $21.56^{a, e}$ \\
\hline \multirow[t]{2}{*}{5} & $22.75^{c}$ & 22.36 & $23.26^{a, d}$ \\
\hline & & & $22.79^{a, e}$ \\
\hline 6 & 22.12 & 22.11 & $--^{b}$ \\
\hline \multirow[t]{2}{*}{7} & $21.46^{c}$ & 21.36 & $21.42^{a, d}$ \\
\hline & & & $20.95^{a, e}$ \\
\hline \multirow[t]{2}{*}{ Mean } & 22.76 & 22.63 & $22.76^{a, d}$ \\
\hline & & & $22.26^{a, e}$ \\
\hline \multirow[t]{2}{*}{$\mathrm{SD}$} & 0.91 & 0.91 & $1.27^{a, d}$ \\
\hline & & & $1.25^{a, e}$ \\
\hline \multirow[t]{2}{*}{ Mean \% error } & - & -0.57 & $-0.74^{a, d}$ \\
\hline & & & $-0.74^{a, e}$ \\
\hline
\end{tabular}

$\mathrm{AL}$, axial length; $\mathrm{ACD}$, anterior chamber depth; $\mathrm{LT}$, lens thickness; $\mathrm{VCD}$, vitreous cavity depth.

${ }^{a}$ Anterior chamber depth, lens thickness and vitreous cavity depth known.

${ }^{b}$ Anterior chamber depth, lens thickness and vitreous cavity depth not known.

${ }^{c}$ For these 4 eyes mean axial length was $22.93 \mathrm{~mm}$; SD 1.22.

${ }^{d}$ Using conversion factor of 0.64 to calculate VCD.

${ }^{e}$ Using conversion factor of 0.62 to calculate VCD.

\section{Discussion}

IOL power calculation is dependent on desired postoperative refractive error, anterior chamber depth factor, average corneal power and, most significantly, the AL of the eye. ${ }^{8}$ It is this fourth variable that is affected by the presence of silicone oil. AL measurement in eyes containing silicone oil in the posterior segment gives inaccurate results, even in the best hands. There is an apparent increase in $\mathrm{AL}$, as measured by echography, in eyes which have had the vitreous replaced with silicone oil, since the speed of sound in silicone oil is slower than in vitreous humour. The speed of sound in silicone oil of viscosity 1000 centistokes is $987 \mathrm{~m} / \mathrm{s}^{8}$ compared with $1532 \mathrm{~m} / \mathrm{s}$ in aqueous and vitreous ${ }^{7-9}$ and $1641 \mathrm{~m} / \mathrm{s}$ through the cornea and cataractous lens ${ }^{7,8}$ (Table 1). The velocity of sound also varies depending on the viscosity of the silicone oil. ${ }^{8}$ The viscosity of the silicone oil used in this study was 1300 centistokes. Sound velocity through this more viscous oil would therefore be expected to be less than $987 \mathrm{~m} / \mathrm{s}$, but the exact velocity is unknown.

The axial echo pattern presents intraocular distances in terms of the time gaps between the returning echoes. The reflected beam is assumed to traverse the same path to return to the transducer as it travelled to reach the

Table 6. Comparison of measured IOL power versus estimated IOL power (using a conversion factor of 0.71 to estimate axial length) required for emmetropia in 7 phakic eyes, using SRK/T calculation formula (A-constant 118.0)

\begin{tabular}{lccc}
\hline Patient no. & $\begin{array}{c}\text { Measured power of IOL }{ }^{a} \text { for } \\
\text { emmetropia, M (dioptres) }\end{array}$ & $\begin{array}{c}\text { Estimated power of IOL for } \\
\text { emmetropia, } E \text { (dioptres) }\end{array}$ & $\begin{array}{c}\text { Difference in emmetropic IOL } \\
\text { power }(E-M)\end{array}$ \\
\hline 1 & 17.90 & 18.30 & +0.40 \\
& & $18.33^{b}$ & $+0.43^{b}$ \\
2 & 22.69 & 23.62 & +0.93 \\
3 & 19.81 & 20.19 & +0.38 \\
4 & 22.18 & 24.25 & +2.07 \\
& & $25.46^{b}$ & $+3.28^{b}$ \\
5 & 21.68 & 22.92 & +1.24 \\
6 & & $20.11^{b}$ & $-1.57^{b}$ \\
7 & 21.59 & 21.62 & +0.03 \\
& 25.21 & 26.29 & +1.08 \\
Median & & $26.08^{b}$ & $+0.87^{b}$ \\
Mean & & +0.93 \\
& & & $+0.65^{b}$ \\
SD & & & 0.88 \\
\hline
\end{tabular}

IOL, intraocular lens.

${ }^{a}$ After removal of silicone oil (viscosity 1300 centistokes).

${ }^{b}$ Using a conversion factor of 0.64 to estimate vitreous cavity depth of silicone oil-filled eye. 
back of the eye. This assumption is valid at the foveal area. ${ }^{11}$ Time units are converted into units of distance measurement by multiplying the transient time by the average speed of sound through the ocular tissues (distance $=$ speed $\times$ time). Unfortunately, when the vitreous is replaced with silicone oil, most commercially available machines are unable to correct for the reduction in sound speed from $1532 \mathrm{~m} / \mathrm{s}$ to $987 \mathrm{~m} / \mathrm{s}$. The depth of the vitreous cavity is therefore overestimated.

Silicone oil forms a sphere due to its high surface tension in water. If the vitreous cavity is not completely filled with silicone oil, the amount of oil the ultrasound beam traverses may vary depending on the position of the patient. When the patient is upright the silicone oil rises, leaving an unfilled area inferiorly. As complete an oil fill as possible was present in all cases so that there was minimal space between the posterior surface of the silicone oil bubble and the anterior surface of the retina with the patient sitting upright. The transducer was oriented so that the ultrasound beam was perpendicular to the globe. The use of B-mode echography confirmed that the AL measurement obtained with the A-scan was accurate and that the retinal spike seen (Fig. 1) was not an artefact. One study has demonstrated that exact localisation of the retina is possible even in the presence of silicone oil. ${ }^{10}$ In our study, the retinal echo was also easily visualised (Fig. 1).

A-scan echography offers a safe, simple and accurate method for the clinical measurement of ocular dimensions. ${ }^{9}$ Present-day A-mode echographic machines have several marker gates. They can therefore recognise the different components of the axial scan and use the appropriate velocity for each tissue. These velocities are preset into the instrument. Measurement of anterior chamber depth (ACD), lens thickness (LT) and vitreous cavity depth (VCD) is therefore possible. Not all biometry machines, however, measure ACD, LT and VCD, and even with the Canon KVI A-scan machine used for this study it was not always possible to measure these parameters because of the high gain required with dense lens opacities.

Additionally, in the presence of silicone oil, the measured AL may be greater than the maximum range of the A-scan apparatus. B-scanning is then required, making measurement of ACD and LT impossible. Although B-scan imaging is useful, one drawback is shortening of the echographic image (Fig. 1), thus introducing errors into the AL measurement. The different components of the axial scan, with the different velocities for each tissue, are not recognised and no adjustment for the increased speed of sound through the cornea and lens (Table 1) is made. The AL of the eye as measured on B-scanning is therefore underestimated. In addition, the average speed of sound through the eye is inversely related to the linear amount of silicone oil traversed by the sound wave. ${ }^{8} \mathrm{AL}_{\mathrm{oil}}$ is directly proportional to $\mathrm{AL}_{\text {without oil }}$. This linear relationship may cease to exist beyond a certain $\mathrm{AL}$ as the average speed of sound in the silicone oil-filled eye decreases. The authors suggest caution if applying the conversion factor determined in this study to very long eyes, since this may result in underestimation of the power of IOL required for a desired post-operative refractive error.

The conversion factor of 0.71 determined in this study is of maximum value when ACD, LT and VCD are not known. If ACD and LT are known, it may be more appropriate to calculate the true VCD. The calculated VCD can then be added to the known ACD and LT to determine the true AL of the eye (Table 5). This may not be applicable to very long eyes for the reasons given above. The ratio of sound velocity oil $(987 \mathrm{~m} / \mathrm{s})$ to sound velocity $_{\text {vitreous }}(1532 \mathrm{~m} / \mathrm{s})$ is 0.64 for silicone oil of viscosity 1000 centistokes. The mean ratio of $\mathrm{VCD}_{\text {without oil }}$ to $\mathrm{VCD}_{\text {oil }}$ in this study was 0.62 with standard deviation 0.02 (and not 0.64 as might be expected), since the viscosity of the silicone oil used was 1300 centistokes. The velocity of sound in silicone oil varies depending on the viscosity of the oil, ${ }^{8}$ being increasingly slower in silicone oils of increasing viscosity. Since the silicone oil used in this study was of viscosity 1300 centistokes, it may be more appropriate to use a conversion factor of 0.62 to estimate the true VCD.

Cataracts frequently form after the use of silicone oil. At present, when trying to decide the size of IOL to be used in eyes undergoing combined cataract extraction, removal of silicone oil and lens implantation, a 'best guess' method is often employed, using measurements obtained from the contralateral eye or the $\mathrm{AL}$ of an average eye. ${ }^{7}$ There are, however, several limitations of these methods. The patient may be anisometropic, or may have only one eye which is not of average length. It is apparent from second eye cataract surgery that desired implant power between the two eyes of one patient often differs. It has been suggested that pre-operative biometry be performed on every phakic patient in whom silicone oil is to be used. The decision to tamponade with silicone oil may, however, only have been reached intraoperatively. In addition, pre-operative biometry could entail measuring AL in eyes with macula off retinal detachments or eyes subsequently treated with scleral buckling, ${ }^{7}$ resulting in inaccurate AL measurement. We believe that it is possible to calculate the true AL in eyes with silicone oil by using a conversion factor of 0.71 (Table 5). This can minimise post-operative refractive errors resulting from inaccurate IOL power calculation. This conversion factor can only be used for silicone oil of viscosity 1300 centistokes. Oils of different viscosity will have a different constant which can be determined in a similar manner. Prospective evaluation of the conversion factor determined in this study is the subject of a future report.

\section{References}

1. Sell CN, McCuen BW II, Landers MB III, Machemer R. Longterm results of successful vitrectomy with silicone oil for advanced oil for advanced P.VR. Am J Ophthalmol 1987;103:24-8.

2. Gonvers M. Temporary silicone oil tamponade in the management of retinal detachment with proliferative vitreoretinopathy. Am J Ophthalmol 1985;100:239-45. 
3. McCartney DL, Miller KM, Stark WJ, Guyton DL, Michels RG. Intraocular lens style and refraction in eyes treated with silicone oil. Arch Ophthalmol 1987;105:1385-7.

4. Grey RHB, Leaver PK. Silicone oil in treatment of massive preretinal retraction. I. Results in 105 eyes. Br J Ophthalmol 1979;63:355-60.

5. Leaver PK, Grey RHB, Garner A. Silicone oil injection in the treatment of massive preretinal retraction. II. Late complications in 93 eyes. Br J Ophthalmol 1979;63:361-7.

6. Jonas JB, Budde WM, Panda-Jonas S. Cataract surgery combined with transpupillary silicone oil removal through planned posterior capsulotomy. Ophthalmology 1998;105:1234-8.

7. Meldrum ML, Aaberg TM, Patel A, Davis J. Cataract extraction after silicone oil repair of retinal detachments due to necrotizing retinitis. Arch Ophthalmol 1996;114:885-92.
8. Hoffer KJ. Ultrasound velocities for axial eye length measurement. J Cataract Refract Surg 1994;20:554-62.

9. McLeod D, Hillman J, Restori M. Ultrasound. Trans Ophthalmol Soc UK 1981;101:137-45.

10. Clemens S, Kroll P, Rochels R. Ultrasonic findings after treatment of retinal detachment by intravitreal silicone instillation. Am J Ophthalmol 1984;98:369-73.

11. Shugar JK, deJuan E Jr, McCuen BW II, Tiedeman J, Landers MR III, Machemer R. Ultrasonic examination of the siliconefilled eye: theoretical and practical considerations. Graefes Arch Clin Exp Ophthalmol 1986;224:361-7.

12. Retzlaff JA, Sanders DR, Kraff MC. Development of the SRK/T intraocular lens power calculation formula. J Cataract Refract Surg 1990;16:333-40. 